A C T A C H E M I C A S C A N D I N A V I C A $26 \quad(1972) \quad 3568-3578$

\title{
On the Internal Rotation of Aromatic Neopentyl Groups
}

\author{
PER M A R T I N S O N*
}

\author{
Department of Organic Chemistry, University of Göteborg and Chalmers Institute of \\ Technology, Fack, S-40220 Göteborg 5, Sweden
}

\begin{abstract}
Some novel compounds, e.g. 2,4-dibromo-5-t-butyl-1,3-dineopentylbenzene and 1,2,3,5-tetraneopentylbenzene, have been prepared and studied by NMR spectroscopy with respect to the internal rotation of aromatic neopentyl groups. The former compound has been found to show slow rotation of the 3-neopentyl group, which was observable as magnetic nonequivalence between the methylene protons in the 1-neopentyl group. Similarly, the latter compound has been found to show slow rotation of the 2-neopentyl group, which induces magnetic nonequivalence between the methylene protons in the 1-as well as in the 3-neopentyl group.

Starting from these observations earlier studies of hindered rotation in some 2,4-dihalo-1,3,5-trineopentylbenzenes as well as in 1,2,3,4tetramethyl-5,6-dineopentylbenzene are discussed and reinterpreted.

A synthesis of 1-t-butyl-3,5-dineopentylbenzene included in the present work represents an example of a new method for the preparation of 1,3,5-trialkylbenzenes with two similar alkyl groups and a dissimilar one.
\end{abstract}

$\mathrm{T}$

he internal rotation of neopentyl groups in aromatic compounds has been studied in some detail by means of NMR spectroscopy. The report by Dix et al. ${ }^{1}$ of hindered rotation in 1,2,3,4-tetramethyl-5,6-dineopentylbenzene (1) has been cited as the first example of hindered rotation around an $s p^{2}-s p^{3}$ carbon-carbon bond. Temperature-dependent AB-type NMR spectra from the 1-and 5-methylene protons in a number of 2,4-disubstituted 1,3,5-trineopentylbenzenes (2) with halo ${ }^{2}$ or nitro/amino substituents have been observed, the latter by the present author (unpublished results).

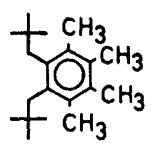

1

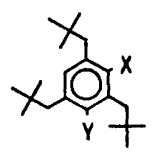

2

\footnotetext{
* Present address: Department of Pharmacology, University of Göteborg, Fack, S-400 33 Göteborg 33, Sweden.
} 
A complete line-shape analysis of the NMR spectra of 2,4-dibromo- and 2,4-dichloro-1,3,5-trineopentylbenzene has been published, ${ }^{3}$ and a similar analysis of up to three temperature-dependent, simultaneously appearing ABpatterns in the NMR spectra of 2-bromo-4-chloro-, 2-bromo-4-iodo-, and 2chloro-4-iodo-1,3,5-trineopentylbenzene has been made recently. ${ }^{4}$ Other related compounds, 2,6-disubstituted neopentylbenzenes, have been studied by Reuvers et al. ${ }^{5}$ They observed restricted rotation in 3-methyl-2-neopentylbenzoic acid and its derivatives.

The study of hindered internal rotation of aromatic neopentyl groups has been based on the fact that the methylene protons of a neopentyl group are diastereotopic in the low-energy rotamers represented by $a$ and $b$ in Fig. 1 if the ortho substituents, $R_{1}$ and $R_{2}$, are not identical. This means that the methylene protons will appear at different chemical shifts and couple with each other to yield an $\mathrm{AB}$-pattern in the NMR spectra at temperatures low enough to permit the observation of $a$ and $b$ separately.

The magnitude of the steric interaction between the $t$-butyl group and the ortho substituents is considered to primarily determine the magnitude of the barriers to rotation. There will be two barriers for conversion of the rotamer $a$ into $b$. The energy maxima correspond to the conformations $c$ and $d$. Thus there are two rate constants $k_{1}$ and $k_{2}$, the sum of which will be experimentally observable. In the special case of identical ortho substituents $\left(\mathrm{R}_{1}=\mathrm{R}_{2}\right)$ the observable rate constant will be $2 k_{1}$. The protons $H_{A}$ and $H_{B}$ will be separately observable in the NMR spectra only if both barriers are high enough to hinder too rapid interconversion between the rotamers $a$ and $b$.

The latter condition can be used to explain the reported ${ }^{3}$ absence of temperature dependence in the NMR spectra of the monohalo-1,3,5-trineopentylbenzenes (down to $-100^{\circ} \mathrm{C}$ ), because each neopentyl group will pass an $o-$ proton easily. Then the temperature-dependence of the 1- and 5-methylene regions in the NMR spectra of the 2,4-disubstituted 1,3,5-trineopentylbenzenes may seem surprising. The 1- and 5-neopentyl groups should easily pass the $o$-proton in the 6-position. Due to this anomaly the published discussion of the temperature-dependence in the NMR spectra of 2,4-dichloro- and 2,4-dibromo1,3,5-trineopentylbenzene was based on the assumption of a concerted disrotatory movement of the 1- and 5-neopentyl groups, involving passage of the halogen by one of the neopentyl groups, thus explaining the observed barrier. The 3-neopentyl group was "tacitly assumed to take care of itself", ${ }^{3,6}$

The present investigation is considered to present support for an alternative explanation of the temperature-dependence in the NMR spectra of 2,4-disubstituted 1,3,5-trineopentylbenzenes in terms of "induced" magnetic nonequivalence.* Let us assume that of the three neopentyl groups only the 3 neopentyl group rotates slowly on the NMR time-scale. At low temperatures the $t$-butyl group in this neopentyl group would be preferentially on one side of the benzene ring plane, and there would be no symmetry between the geminal protons in each of the 1- and 5-methylene groups. They would be dia-

* The phenomenon of magnetic nonequivalence of geminal groups induced by hindered rotation in achiral molecules has been discussed by Kessler, who studied aryl-nitrogen barriers in for example 2,6-diisopropylacetanilide. ${ }^{7}$ Barriers of similar type have also been observed in 2,4,6. trineopentylacetanilide by the present author.

Acta Chem. Scand. 26 (1972) No. 9 
stereotopic despite their own rapid rotation and would give rise to $A B$-patterns in the NMR spectra. The 3-methylene protons would appear as a singlet at all temperatures provided that the two substituents are identical.

The ideal molecule with which one could test the above hypothesis would be 2,4-dibromo-3-t-butyl-1,5-dineopentylbenzene (3). This compound has the same characteristics as 2,4-dibromo-1,3,5-trineopentylbenzene $(2, \mathrm{X}=\mathrm{Y}=\mathrm{Br})$ except that the 3-neopentyl group has been replaced by a $t$-butyl group, which should not disturb the symmetry between the methylene protons in the 1and 5-positions in the way the neopentyl group in $(2)$ is assumed to do.* Consequently, (3) should not give rise to an AB-pattern in its NMR spectrum if the hypothesis is valid. Due to expected difficulties in the synthesis of (3), with two bromines ortho to a $t$-butyl group, the following somewhat less straight-forward - but synthetically easier - way of testing the hypothesis was chosen.

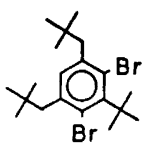

3

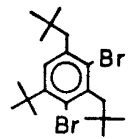

4

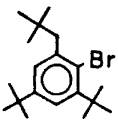

5

The two new compounds 2,4-dibromo-5-t-butyl-1,3-dineopentylbenzene (4) and 2-bromo-3,5-di-t-butylneopentylbenzene (5) were prepared and studied by means of NMR spectroscopy. The compound (5) differs from (4) in the same way that (3) differs from $(2, \mathrm{X}=\mathrm{Y}=\mathrm{Br})$ - by replacement of the 3 neopentyl group by a $t$-butyl group. The compound (5) also lacks the 4-bromine, which is present in (4), but this is considered to be of no importance in the present context.

The mononeopentyl compound (5) was observed to exhibit a methylene singlet down to about $-100^{\circ} \mathrm{C}$ in methylene chloride, while the dineopentyl compound (4) showed an AB-pattern for the 1-neopentyl group at lower temperatures. The 1-neopentyl group is surrounded by an $o$-bromine and an $o$ proton in (4) as well as in (5). The cause of the difference in behaviour between these two compounds must then be traced to the alkyl group in the 3-position. The 1-methylenes in (4) are diastereotopic at low temperatures because the 3-neopentyl group destroys the symmetry about the ring-plane in line with the assumptions above. The same reasoning is valid for 2,4-disubstituted 1,3,5trineopentylbenzenes, in which the 1- and 5-neopentyl groups oscillate past the 6-proton rapidly on the NMR time-scale, but the 3-neopentyl group has a rotational barrier that can be studied by the NMR kinetic method. This barrier is identical to that previously assigned to the rotation of the 1- and 5neopentyl groups. ${ }^{3}$

An exact determination of the activation parameters for the barrier in (4) is planned in collaboration with Mr. B. Nilsson of the Lund Institute of Technology, and the magnitude of the rotational energy barrier is expected

* It is unclear if a $t$-butyl group surrounded by two ortho bromines would rotate freely. ortho $t$-Butyl groups in 2,4,6-tri-t-butylbromobenzene have a barrier to rotation lower than about $8 \mathrm{kcal} / \mathrm{mol}^{8}$ 
to closely equal that determined ${ }^{3}$ for 2,4-dibromo-1,3,5-trineopentylbenzene, i.e. $\Delta G^{\neq} \approx \Delta H^{\ddagger} \approx 16.2 \mathrm{kcal} / \mathrm{mol}$.

When $\mathrm{X} \neq \mathrm{Y}$ in (2) as many as three, simultaneously appearing methylene AB spectra have been observed. ${ }^{2}$ The recent NMR analysis of some dihalotrineopentylbenzenes with different halogens gave the same barrier from all three patterns in each compound. ${ }^{4}$ This must mean that they are not independent but all emanate from the same rate process. This process is now readily thought of as the slow rotation of the 3-neopentyl group inducing magnetic nonequivalence in the 1- and 5-methylene groups. Thus the magnitude of the barrier for this hindered rotation would be expected to be largely determined by the size of the smaller ortho substituent. This is also the case, as the $\Delta G^{\neq}$ values found for 2-bromo-4-chloro- and 2-chloro-4-iodo-1,3,5-trineopentylbenzene $\left(14.7 \pm 0.5\right.$ and $14.6 \pm 0.4 \mathrm{kcal} / \mathrm{mol}$, respectively) ${ }^{4}$ are very similar and closely equal that found for 2,4-dichloro-1,3,5-trineopentylbenzene $(14.3 \pm 0.2 \mathrm{kcal} / \mathrm{mol}) .^{3}$ Similarly, the $\Delta G^{\neq}$value found for 2 -bromo-4-iodo$1,3,5$-trineopentylbenzene $(16.7 \pm 0.4 \mathrm{kcal} / \mathrm{mol})^{4}$ compares well with that measured for 2,4-dibromo-1,3,5-trineopentylbenzene $(16.2 \pm 0.1 \mathrm{kcal} / \mathrm{mol}){ }^{3}{ }^{3}$ An estimation of the relative magnitudes of $k_{1}$ and $k_{2}$ in Fig. $1\left(\mathrm{R}_{1}=\mathrm{Cl}, \mathrm{R}_{2}=\mathrm{Br}\right)$ in the bromochloro derivative can be made from the difference in $\Delta G^{\neq}, 1.9$ $\mathrm{kcal} / \mathrm{mol}$, between the dibromo and dichloro derivatives by application of the Eyring equation. ${ }^{9}$ This indicates that about $96 \%$ of the rotations are past the chlorine and about $4 \%$ past the bromine at $298 \mathrm{~K}$. Thus the observable rate constant in the bromochloro derivative is close to $k_{1}$ (see Fig. 1) but equals $2 k_{1}$ in the dichloro derivative. A difference of about $0.4 \mathrm{kcal} / \mathrm{mol}(R T \ln 2)$ is to be expected in a comparison of the $\Delta G^{\neq}$values of these compounds.

It seems pertinent in this connection to mention an observation of hindered rotation in an additional dihalotrineopentylbenzene. 2-Chloro-4-fluoro-1,3,5trineopentylbenzene, when studied at $100 \mathrm{MHz}$ and $25^{\circ} \mathrm{C}$, showed three methylene absorptions, two of which were split by coupling to fluorine. ${ }^{10}$
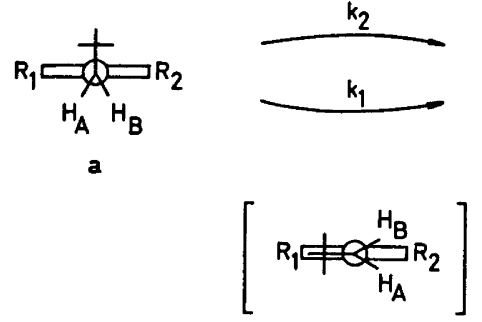

d

Fig. 1. Pathways for interconversion of aromatic neopentyl rotamers, $a$ and $b$, via the transition states $c$ and $d . R_{1}$ and $R_{2}$ are ortho substituents.
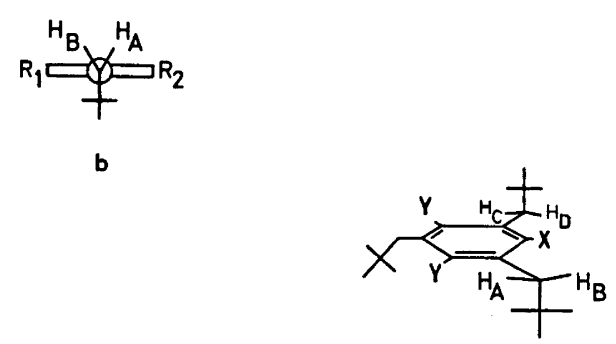

Fig. 2. A low-energy rotamer of $2-\mathrm{X}-4,6$ $\mathrm{Y}_{2}$-1,3,5-trineopentylbenzene, showing the magnetically nonequivalent methylene protons $\mathrm{H}_{\mathrm{A}}, \mathrm{H}_{\mathrm{B}}, \mathrm{H}_{\mathrm{C}}$ and $\mathrm{H}_{\mathrm{D}}$.

Acta Chem. Scand. 26 (1972) No. 9 
When the temperature was lowered all three sets of peaks gradually broadened, the singlet corresponding to the I-methylenes most rapidly (as expected from a largest $\Delta v_{\mathrm{AB}}$ in this methylene group). From an approximate temperature of collaps of about $-90^{\circ} \mathrm{C}$ and the use of the shift and coupling constant determined for the 1-and 5-methylene groups from low-temperature spectra of 2,4-dichloro-1,3,5-trineopentylbenzene $\left(\Delta v=20.0 \mathrm{~Hz} \text { and } J_{\mathrm{AB}}=13.3 \mathrm{~Hz}\right)^{3}$ a very approximate free energy of activation at the temperature of coalescence of $9 \mathrm{kcal} / \mathrm{mol}$ was calculated. This represents the passage of a fluorine by the neopentyl group.

The replacement of the aromatic proton in $(2)$ with a larger substituent $Y$ to give a $2-\mathrm{X}-4,6-\mathrm{Y}_{2}-1,3,5$-trineopentylbenzene should have the effect of restricting the rotation of the 1 - and 5-neopentyl groups as well. This would allow the observation of simultaneously appearing "direct" and "induced" magnetic nonequivalence in the same molecule. The nonequivalence between the A and $\mathrm{B}$ protons (as well as between the $\mathrm{C}$ and $\mathrm{D}$ ones) in the rotamer shown in Fig. 2 would arise because of the difference between the $\mathrm{X}$ and $\mathrm{Y}$ substituents. The nonequivalence between the $\mathrm{A}$ and $\mathrm{C}$ and between the $\mathrm{B}$ and $\mathrm{D}$ protons would be induced by the 5-neopentyl group. Preliminary NMR studies
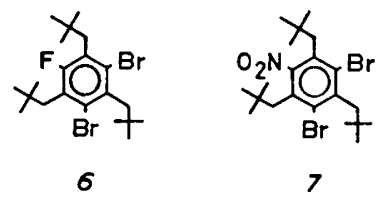

of the two compounds 2,4-dibromo-6-fluoro-1,3,5-trineopentylbenzene $(6)^{10}$ and 2,4-dibromo-1,3,5-trineopentyl-6-nitrobenzene ( 7$)^{11}$ have given support for such an analysis, and a study of the latter compound will be reported separately.

Another observation has been made that strongly supports the present interpretation of the rotational behaviour of aromatic neopentyl groups. 1,2,3,5-Tetraneopentylbenzene (8) has been found to give an AB-pattern for

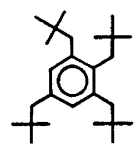

8

the four ortho methylene protons in the 1-and 3-positions in NMR spectra recorded at probe temperature and 60 or $100 \mathrm{MHz}$. This spectral behaviour is explained by the hindered rotation of the 2-neopentyl group, inducing the magnetic nonequivalence between the ortho methylenes. In this case the spectrally temperature-dependent methylene protons are surrounded by an $o$ proton and the chirality-inducing neopentyl group in the other ortho position. The neopentyl group which is restricted in its rotation has to pass an $o$-neopentyl substituent. It is pertinent in this connection to report that 2 -methyl- 
1,3,5-trineopentylbenzene does not give rise to similar complexities in its low-temperature spectrum.

An approximate determination of the free energy of activation at the temperature of coalescence (about $355 \mathrm{~K}$ at $60 \mathrm{MHz}$ ) for (8) in $\mathrm{CDBr}_{3}$ gives a value of $17.3 \mathrm{kcal} / \mathrm{mol}$. If this would be considered to represent a pure neopentylmethylene barrier, one could have expected a value smaller than that measured for passage of a bromine substituent, $16.2 \mathrm{kcal} / \mathrm{mol} .^{3}$ The van der Waals volume of a methyl substituent $\left(13.67 \mathrm{~cm}^{3} / \mathrm{mol}\right)$ is smaller than that of an aromatic bromine substituent $\left(15.12 \mathrm{~cm}^{3} / \mathrm{mol}\right){ }^{12}$ Recent data from nitration studies of substituted 1,3,5-trineopentylbenzenes indicate as well that the methyl group is smaller than a bromine in its interaction with an o-neopentyl group. ${ }^{13}$ The discrepancy of about $1 \mathrm{kcal} / \mathrm{mol}$ in the opposite direction between the two neopentyl barriers may thus be taken as an indication that the $t$-butyl moieties of the 1-and 3-neopentyl groups contribute to the rotational barrier of the 2-neopentyl group.

The present study has some bearing on the analysis of the rate processes in 1,2,3,4-tetramethyl-5,6-dineopentylbenzene (1) as well. Dix et al. ${ }^{1}$ reported that the methylene protons gave an $\mathrm{AB}$-pattern at temperatures below room temperature, due to geminal nonequivalence. This pattern collapsed to a single broad line at about $55^{\circ} \mathrm{C}$. The rotamer of lowest energy was considered to have the two neopentyl groups on opposite sides of the ring. A concerted rotation in a conrotatory fashion was suggested to account for the spectral equivalence of the methylene protons at higher temperatures. In this way the methylene protons pass each other and the $t$-butyl groups are always as far apart as possible. Thus Dix et al. considered the interaction between the methylene protons in the neopentyl groups as the major source of the rotational barrier in (1). This barrier has been discussed to some extent in the review literature as well. Binsch has suggested the following addition to the original interpretation of Dix et al.: "Extreme steric crowding prevents the two benzene-to-neopentyl bonds from being coplanar in the conformation of lowest energy, causing the methylene protons to become diastereotopic". ${ }^{14}$ Siddall and Stewart agree with the original authors that the slow rotation of the neopentyl groups is due to steric factors but are considering the interaction between the $t$-butyl group in one neopentyl group and the adjacent neopentyl group as the major source of the rotational barrier. ${ }^{15}$ However, as shown in the present investigation, it is the interaction between a neopentyl group and the smaller of the ortho substituents that primarily determines the magnitude of the rotational barrier, and consequently the measured barrier in (1) is probably primarily a neopentyl-methyl barrier. The interpretation of Dix et al. ${ }^{1}$ in terms of a methylene-methylene barrier also seems less probable if the $\Delta G^{\neq}$value of 16 $\mathrm{kcal} / \mathrm{mol}$, estimated from their data, is compared with the height of the barrier to internal rotation in $o$-xylene, $2 \mathrm{kcal} / \mathrm{mol} .^{16}$

It is the opinion of the present author that the rotation of the neopentyl groups in (1) does not have to be concerted, although a conformer with two $t$-butyl groups on the same side of the ring plane would certainly be less stable than one with the $t$-butyl groups on each side. It is also believed that any non-coplanarity of the benzene-to-neopentyl bonds does not have to be taken into account in the low-energy rotamers. On these premises it seems probable

Acta Chem. Scand. 26 (1972) No, 9 
that 1,2-dineopentylbenzene would not show restricted rotation, but in molecules of the type 1-X-2,3-dineopentylbenzene there would be a barrier for the internal rotation of the 2 -neopentyl group, which would be observable in the 3-neopentyl group by the NMR kinetic method.

A molecule containing a neopentyl group conformationally locked into the plane of the benzene ring should be of interest as a model for the transition state of the rotation of an aromatic neopentyl group. Two obvious examples have been reported in the literature. The bicyclic compound $(9)^{17}$ can be looked upon as representing the transition state for passage of the fluorine in an $o-$ fluoroneopentylbenzene. It was reported that (9) shows hindered rotation of the $t$-butyl group up to very high temperatures $\left(>200^{\circ} \mathrm{C}\right)$. This indicates a

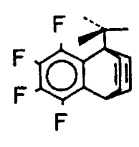

9

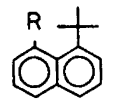

10

sizeable barrier for the passage of a neopentyl group past even the relatively small fluorine substituent. However, as mentioned above, the magnitude of such a barrier has been estimated to be of the order of $9 \mathrm{kcal} / \mathrm{mol}$. This may indicate that the rotation of a neopentyl group around the methylene-aryl bond must be coupled with the internal rotation of the $t$-butyl moiety to minimize the $t$-butyl-fluorine interaction. There is probably also some bending at the methylene carbon in order to straighten the neopentyl group somewhat and possibly some distortion of the benzene ring.

The other type of molecule that can be taken as a crude model for the transition state in the rotation of an aromatically bonded neopentyl group is peri-substituted 1-t-butylnaphthalene (10). There are unfortunately very few compounds of this type reported in the literature. Franck and Yanagi have reported the synthesis of 1,4-di-t-butylnaphthalene, -5-naphthol, and -5-naphthyl acetate. ${ }^{18}$ They do not report any hindered rotation of the $t$-butyl group in these compounds at the temperature of the NMR probe and do not give any low-temperature data. They do report, however, a nuclear Overhauser effect amounting to a $15 \%$ increase in the integrated intensity of the periproton in 1,4-di-t-butylnaphtalene, when the peak representing the $t$-butyl group was saturated.

\section{EXPERIMENTAL}

NMR spectra were recorded on Varian A-60 or HA-100 spectrometers equipped with Varian variable temperature controllers. TMS was used as internal standard for the chemical shift measurements; shifts are reported in ppm downfield from TMS. The multiplicities of the peaks are given as singlet $(s)$, doublet (d), triplet $(t)$, and quartet $(q)$. The temperature of the probe of each instrument was used unless otherwise noted.

$$
\text { 2,4- Dibromo-5- } t \text { - but y l-1,3-dineopent yl benzene }
$$

2,4-Dibromo-5-t-butyl-1,3-dineopentylbenzene (4) was prepared according to Scheme 1. Two moles of methyl neopentyl ketone were co-trimerized with one mole of pinacolone with the help of sodium hydride to yield 1-t-butyl-3,5-dineopentylbenzene (11). This 

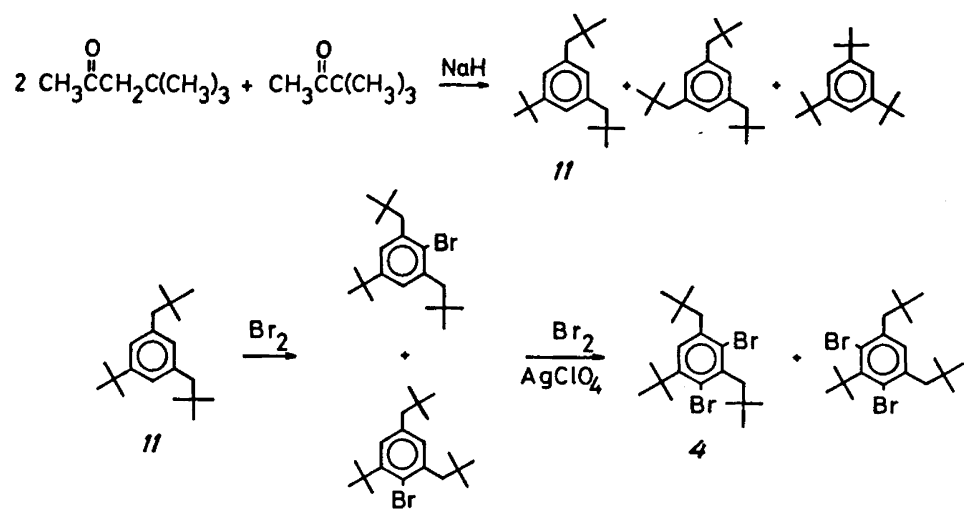

Scheme 1. Preparation of 2,4-dibromo-5-t-butyl-1,3-dineopentylbenzene (4).

represents a modification of a published method of synthesizing 1,3,5-trineopentylbenzene by trimerizing three moles of methyl neopentyl ketone. ${ }^{19}$ The "mixed" trialkylbenzene was prepared by a two-step procedure in order to optimize the yield of the desired product and avoid a more statistical spread among the possible products. The two moles of methyl neopentyl ketone were condensed with each other before the pinacolone was added. In this way the crude product contained as much as $50-60 \%$ of 11 as well as $35-40 \%$ of 1,3,5-trineopentylbenzene and $5-10 \%$ of $1,3,5$-tri-t-butylbenzene. Efforts to improve the yield of 11 by varying the proportions of reactants, time of individual reaction steps or catalyst $(\mathrm{LiH})$ resulted in lower yields.

Bromination of 11 with an excess of bromine in dimethylformamide yielded a mixture of two monobromo isomers-2-bromo-5-t-butyl-1,3-dineopentylbenzene (78\%) and 4bromo-5-t-butyl-1,3-dineopentylbenzene $(22 \%)$.

This mixture of monobromo isomers was brominated with $1 \mathrm{~mol}$ of bromine and silver perchlorate in acetic acid-dioxane to yield 2,4-dibromo-5-t-butyl-1,3-dineopentylbenzene (4), which was contaminated by less than $5 \%$ (GLC) of what was indicated by NMR to be the 4,6-dibromo derivative. The impurity did not disturb the NMR measurements and the compound was not purified further.

1-t-Butyl-3,5-dineopentylbenzene (11). Sodium hydride (12 $\mathrm{g}$ of $50 \%$ oil dispersion, $0.25 \mathrm{~mol}$ of $\mathrm{NaH}$ ) was washed twice by decantation with dried hexane in a $500 \mathrm{ml}$ three. necked flask. After the final washing $100 \mathrm{ml}$ of diglyme, freshly distilled from calcium hydride, was added and the flask was equipped with a magnetic stirring bar, a reflux condenser with a drying tube, an addition funnel and a thermometer. All glass pieces had been dried in an oven and cooled in a desiccator before use. All operations were carried out under nitrogen. Methyl neopentyl ketone $(28.55 \mathrm{~g}, 0.25 \mathrm{~mol})$ was added rather rapidly from the addition funnel under stirring at room temperature. Heating to about $80^{\circ} \mathrm{C}$ initiated an exothermic reaction. The flask was left at $50^{\circ} \mathrm{C}$ overnight.

Pinacolone $(12.5 \mathrm{~g}, 0.125 \mathrm{~mol})$ was added in one portion and the mixture was refluxed for $12 \mathrm{~h}$. After cooling, the mixture was poured into about $500 \mathrm{ml}$ of water and neutralized with $50 \%$ sulphuric acid. Extraction twice with cyclohexane and washing of the combined organic phases with water followed by drying over anhydrous magnesium sulphate and evaporation of the solvent yielded an oil that was distilled in vacuo, b.p. $140-150^{\circ} \mathrm{C}$ at 13 torr. The distillate was dissolved in $50 \mathrm{ml}$ of cyclohexane and washed repeatedly with $10 \mathrm{ml}$ portions of ice-cold concentrated sulphuric acid until the coloured impurities were removed. After washing with water, dilute sodium carbonate solution and saturated sodium chloride solution, in that order, the organic solution was dried over magnesium sulphate. Evaporation of the solvent yielded $13.0 \mathrm{~g}$ of a mixture of 1-t-butyl-3,5-dineopentylbenzene, 1,3,5-trineopentylbenzene and 1,3,5-tri-t-butylbenzene, which was separated on an Aerograph A 700 gas chromatograph with a $4 \mathrm{~m} \times 0.25 \mathrm{in}$. column of $20 \%$ silicone gum rubber on Chromosorb W 60-80 mesh. Due to formation of aerosols the

Acta Chem. Scand. 26 (1972) No. 9 
recovery varied and was generally not very good, but about $2.5 \mathrm{~g}$ of 1-t-butyl-3,5-dineopentylbenzene was generally recovered.

$N M R\left(C l_{4}\right) 0.89(\mathrm{~s}, 18 \mathrm{H}, t$-butyl), $1.24(\mathrm{~s}, 9 \mathrm{H}, t$-butyl), 2.43 (s, $4 \mathrm{H}$, methylene), $6.62(\mathrm{t}, J=1.5 \mathrm{~Hz}, 1 \mathrm{H}$, aromatic), $6.88(\mathrm{~d}, J=1.5 \mathrm{~Hz}, 2 \mathrm{H}$, aromatic).

2- and 4-Bromo-5-t-butyl-1,3-dineopentylbenzene. To a solution of $52.8 \mathrm{mg}(0.192$ mmol) of 11 in $3 \mathrm{ml}$ of dimethylformamide a solution of $0.06 \mathrm{ml}(1.2 \mathrm{mmol})$ of bromine in $1 \mathrm{ml}$ of dimethylformamide was added in one portion. The mixture was kept in the dark at room temperature for $3 \mathrm{~h}$ with occasional shaking before it was diluted with 50 $\mathrm{ml}$ of an aqueous solution that was $10 \%$ in sodium carbonate and $10 \%$ in sodium sulphite. Extraction with cylohexane, which was then washed with water, dried over magnesium sulphate and evaporated, yielded $67.0 \mathrm{mg}(99 \%)$ of a mixture of monobromo isomers. Integration of the NMR peaks as well as the GLC peaks showed the composition to be $78 \%$ of 2 -bromo-5-t-butyl-1,3-dineopentylbenzene and $22 \%$ of 4-bromo-5-t-butyl1,3-dineopentylbenzene. In one experiment the 2 -bromo isomer was purified by recrystallization from absolute ethanol and its NMR spectrum determined.

$N M R$ spectrum of the 2-bromo isomer $\left(\mathrm{CCl}_{4}\right): 0.97(\mathrm{~s}, 18 \mathrm{H}, t$-butyl), $1.29(\mathrm{~s}, 9 \mathrm{H}$, $t$-butyl), 2.81 (s, $4 \mathrm{H}$, methylene), 6.99 (s, 2H, aromatic).

The NMR spectrum of the 4-bromo isomer $\left(\mathrm{CCl}_{4}\right)$ was extracted from the spectrum of the mixture of the two isomers. A doublet at $6.78 \mathrm{ppm}(J=2.3 \mathrm{~Hz})$ was assigned to the aromatic 2-proton, while the aromatic 6-proton was partly hidden under the aromatic singlet at $6.99 \mathrm{ppm}$ from the 2 -bromo isomer. Two singlets at 2.40 and $2.85 \mathrm{ppm}$ were assigned to the 1- and 3-methylenes, respectively. A singlet at $1.51 \mathrm{ppm}$ was assigned to the 5-t-butyl group. A singlet at $0.92 \mathrm{ppm}$ was assigned to the $t$-butyl moiety of the 1-neopentyl group, while the signal from the $t$-butyl protons in the 3-neopentyl group was probably hidden under the large singlet at $0.97 \mathrm{ppm}$ due to the 2 -bromo isomer.

2,4-Dibromo-5-t-butyl-1,3-dineopentylbenzene (4). A solution of $134.0 \mathrm{mg}(0.38 \mathrm{mmol})$ of the above-mentioned mixture of monobromo isomers in $3 \mathrm{ml}$ of dioxane was mixed with a solution of $100 \mathrm{mg}(0.48 \mathrm{mmol})$ of silver perchlorate in $12 \mathrm{ml}$ of acetic acid. The resulting solution was stirred magnetically and $0.02 \mathrm{ml}(0.39 \mathrm{mmol})$ of bromine in $1 \mathrm{ml}$ of dioxane was added. The mixture was stirred overnight at room temperature, before it was filtered. The precipitated silver bromide was washed with $50 \mathrm{ml}$ of cyclohexane and the combined organic phases were washed with $10 \%$ sodium hydroxide solution followed by water to neutral reaction. The crude product (shown by GLC to contain mainly one component) was chromatographed on a column of alumina. Elution with hexane yielded the desired dibromo isomer that was more than $95 \%$ pure according to GLC. The major contaminant was indicated by NMR to be the 4,6-dibromo isomer. The product was used in the NMR measurements without further purification.

$N M R\left(C D C l_{\mathrm{s}}\right): 0.99(\mathrm{~s}, 9 \mathrm{H}, t$-butyl), 1.07 (s, 9H, $t$-butyl), $1.44(\mathrm{~s}, 9 \mathrm{H}, t$-butyl), 2.8 (broad absorption that appears as a quartet at lower temperatures, $2 \mathrm{H}$, methylene), 3.35 (s, 2H, methylene), 7.47 ( $\mathrm{s}, 1 \mathrm{H}$, aromatic).

\section{2 - B r o m o- 3,5-di-t-butylneopent ylbenzene}

To a solution of $342 \mathrm{mg}$ (1.5 mmol) of 1,3-di-t-butyl-5-neopentylbenzene * in $5 \mathrm{ml}$ of dimethylformamide, $1.0 \mathrm{~g}(6.0 \mathrm{mmol})$ of bromine in $5 \mathrm{ml}$ of dimethylformamide was added in one portion. The mixture was left in the dark at room temperature for 2.5 $h$, after which time GLC analysis indicated that the reaction was complete. The reaction mixture was diluted with $100 \mathrm{ml}$ of water and extracted with cyclohexane. The organic phase was washed with dilute sodium hydroxide solution followed by water to neutral reaction. Drying over magnesium sulphate and evaporation yielded $450 \mathrm{mg}(98 \%)$ of 5 that was more than $99 \%$ pure according to GLC.

$N M R\left(C C l_{4}\right): 0.97$ (s, $9 \mathrm{H}, t$-butyl), 1.30 (s, $9 \mathrm{H}, t$-butyl), $1.55(\mathrm{~s}, 9 \mathrm{H}, t$-butyl), 2.86 (s, $2 \mathrm{H}$, methylene), 7.02 (d, $J=2.5 \mathrm{~Hz}, 1 \mathrm{H}$, aromatic), 7.28 (d, $J=2.5 \mathrm{~Hz}, 1 \mathrm{H}$, aromatic).

* This compound was isolated by distillation (b.p. $110^{\circ} \mathrm{C}, 3$ torr) of a crude product mixture obtained from the coupling of 1 -bromomethyl-3,5-di-t-butylbenzene and $t$-butyl magnesium chloride. The mixture was kindly supplied by Professor Philip C. Myhre. The two major com. ponents of the mixture were 1,2-bis(3,5-di-t-butylphenyl)ethane and 3,5-di-t-butyltoluene.

Acta Chem. Scand. 26 (1972) No. 9 


\section{$1,2,3,5$ - Tetraneopentylbenzene (8)}

A solution of $672 \mathrm{mg}(2.0 \mathrm{mmol})$ of 2 -chloromethyl-1,3,5-trineopentylbenzene in 10 $\mathrm{ml}$ of hexane was cooled with ice under nitrogen. The solution was magnetically stirred while $1 \mathrm{ml}$ of a $2.56 \mathrm{M}$ solution of $t$-butyllithium was slowly added dropwise. The stirring was continued at room temperature for $6 \mathrm{~h}$, before the mixture was refluxed for $1 \mathrm{~h}$ and treated with saturated aqueous ammonium chloride solution. The organic products were extracted with ether and the combined ether extracts were dried over magnesium sulphate and evaporated. A semi-solid remained that was allowed to crystallize maximally before it was filtered by suction. The solid was washed with a small amount of cold carbon tetrachloride on the filter and the combined filtrates were evaporated. A small amount of solid separated, for which reason another filtration was made. The resulting oil was shown by NMR to consist of about $60 \%$ of 1,2,3,5-tetraneopentylbenzene and about $40 \%$ of 2-methyl-1,3,5-trineopentylbenzene, which could be separated by elution with hexane from a column of silica gel.* 1,2,3,5-Tetraneopentylbenzene was eluted before 2-methyl1,3,5-trineopentylbenzene. The filtered solid from above was recrystallized from benzeneethanol (1:1) and shown by NMR to be 1,2-bis(2,4,6-trineopentylphenyl)ethane.

$N M R$ spectrum of (8) in $C C l_{4}: * 0.83(\mathrm{~s}, 9 \mathrm{H}, t$-butyl), $0.86(\mathrm{~s}, 18 \mathrm{H}, t$-butyl), $0.92(\mathrm{~s}$, $9 \mathrm{H}, t$-butyl), 2.37 (s, $2 \mathrm{H}$, methylene), 2.64 (q, $J=13.6 \mathrm{~Hz}, \Delta v=0.94 \mathrm{ppm}, 4 \mathrm{H}$, methylene), $2.78(\mathrm{~s}, 2 \mathrm{H}$, methylene), $6.68(\mathrm{~s}, 2 \mathrm{H}$, aromatic).

NMR spectrum of 1,2-bis(2,4,6-trineopentylphenyl)ethane $\left(C C l_{4}\right): 0.87(\mathrm{~s}, 36 \mathrm{H}, t$ butyl), 0.92 (s, 18H, $t$-butyl), 2.39 (s, 4H, methylene), 2.46 (s, 8H, methylene), 2.79 (s, 4H, ethylene), 6.64 (s, 4H, aromatic).

Acknowledgements. It is a great pleasure to acknowledge the hospitality of Professor Philip C. Myhre during a stay at the Department of Chemistry, Harvey Mudd College, Claremont, California, USA, where part of this work was initiated. Fruitful cooperation with Dr. Robert E. Carter and Mr. Bertil Nilsson is gratefully acknowledged. The author also thanks Professor Lars Melander for reading the manuscript prior to publication. Generous financial support has been received from the Swedish Natural Science Research Council. A Fulbright travel grant (1969-1970) is gratefully acknowledged. Financial support has also been received from the Ograduerade forskares fond at the University of Göteborg. Dr. Robert E. Carter gave linguistic help.

\section{REFERENCES}

1. Dix, D. T., Fraenkel, G., Karnes, H. A. and Newman, M. S. Tetrahedron Letters 1966517.

2. Márton, J. and Martinson, P. Acta Chem. Scand. 23 (1969) 3187.

3. Carter, R. E., Márton, J. and Dahlqvist, K.-I. Acta Chem. Scand. 24 (1970) 195.

4. Nilsson, B., Carter, R. E., Dahlqvist, K.-I. and Márton, J. Org. Magn. Resonance 4 (1972) 95 .

5. Reuvers, A. J. M., Sinnema, A., Nieuwstad, Th. J., van Rantwijk, F. and van Bekkum, H. Tetrahedron 27 (1971) 3713.

6. Carter, R. E. Abstracts of Gothenburg Dissertations in Science 16 (1969).

7. Kessler, H. Tetrahedron 24 (1968) 1857.

8. Myhre, P. C., Edmonds, J. W. and Kruger, J. D. J. Am. Chem. Soc. 88 (1966) 2459.

9. Glasstone, S., Laidler, K. J. and Eyring, H. The Theory of Rate Processes, McGraw, New York 1941, p. $195 \mathrm{ff}$.

10. Martinson, P. Acta Chem. Scand. 26 (1972) 3529.

11. Nilsson, B., Martinson, P., Olsson, K. and Carter, R. E. To be published.

12. Bondi, A. Physical Properties of Molecular Crystals, Liquids and Glasses, Wiley, New York 1968, pp. 453-468.

13. Olsson, K. Acta Chem. Scand. 26 (1972) 3555.

* Found by Mr. Erik Dahlberg at this department.

Acta Chem. Scand. 26 (1972) No. 9 
14. Binsch, G. In Eliel, E. L. and Alllinger, N. L., Eds., Topics in Stereochemistry, Interscience, New York 1968, Vol. 3, p. 130.

15. Siddall, T. H. and Stewart, W. E. In Emsley, J. W., Feeney, J. and Sutcliffe, L. H., Eds., Progress in Nuclear Magnetic Resonance, Pergamon, Oxford 1969, Vol. 5, p. 71.

16. Ingham, K. C. and Strickler, S. J. J. Chem. Phys. 53 (1970) 4313.

17. Brewer, J. P. N., Heaney, H. and Marples, B. A. Chem. Commun. 196727.

18. Franck, R. W. and Yanagi, K. J. Org. Chem. 33 (1968) 811.

19. Martinson, P. and Márton, J. Acta Chem. Scand. 22 (1968) 2382.

Received April 12, 1972. 